\title{
Analisis Laba atas Ekuitas dan Inflasi terhadap Stock Price
}

\author{
Dian Efriyenty ${ }^{1}$ \\ Fakultas Ilmu Sosial dan Humanioura \\ Universitas Putera Batam, Indonesia
}

\begin{abstract}
Surel : dianefriyenty@gmail.com
ABSTRAK

Fenomena beberapa company mengalami fluktuatif stock price yang dapat memicu terhadap inflasi dan laba atas ekuitas. Tujuan research pada implementasi dari menganalisa laba atas ekuitas dan inflasi pada stock price. Populasi dalam survei adalah 49 industri barang konsumen tahun 2015-2019. Sampel yang dilakuka dengan purposive sampling untuk 10 unit usaha. Penganalisi data research dengan bantuan pengujian sendiri dan uji bersamaan. Hasil uji bersamaan menunjukkan laba atas ekuitas berdampak, sedangkan inflasi tidak signifikan. Sedangkan secara bersamaan laba atas ekuitas dan inflasi berdampak pada stock price.
\end{abstract}

Kata Kunci: $\quad$ Laba Atas Ekuitas; Inflasi; Stock Price.

\section{Analysis of Return on Equity and Inflation against Stock Price}

\section{ABSTRACT}

The phenomenon of several companies experiencing stock price fluctuations can affect inflation and return on equity. The research objective is to implement the analysis of return on equity and inflation in stock prices. The population in the survey was 49 consumer goods industries in 2015-2019. Samples were carried out by purposive sampling for 10 business units. Research data analyzers with the help of self-testing and concurrent testing. The joint test results show the impact of return on equity, inflation is not significant. Meanwhile, the return on equity and inflation simultaneously have an impact on share prices.

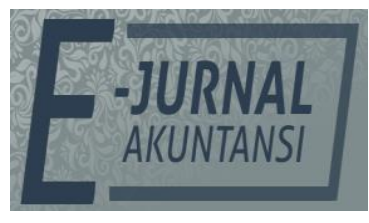

e-ISSN 2302-8556

Vol. 31 No. 4

Denpasar, April 2021

Hal. 976-984

DOI:

10.24843/EJA.2021.v31.i04.p14

PENGUTIPAN:

Efriyenty, D. (2021). Analisis Laba atas Ekuitas dan Inflasi terhadap Stock Price. E-Jurnal Akuntansi, 31(4), 976-984

RIWAYAT ARTIKEL:

Artikel Masuk:

27 Desember 2020

Artikel Diterima: 24 April 2021

Keywords: $\quad$ Return On Equity; Inflation; Stock Price.

Artikel dapat diakses : https://ojs.unud.ac.id/index.php/Akuntansi/index 


\section{PENDAHULUAN}

Pada berbagai perusahaan keuntungan dari kegiatan investasi merupakan modal utama (Fenni, 2015 : 36). Untuk tahun 2015-2019 total saham customer good industry mengalami fluktuatif dari tahun $2015 \mathrm{Rp} 2.009 .960$ menjadi Rp 1.049.240 pada tahun 2017 menurun jauh sebesar Rp 620.908. Sedangkan pada tahun 2018 mengalami pelonjakan yaitu Rp 389.439 sehingga menjadi Rp 231.469. Bahkan total saham menurun kembali di Tahun 2019 menjadi Rp 212.654. Penurunan ini dapat menyebabkan psikologi pasar, risiko sistematik.

Tabel 1. Laba Atas Ekuitas Unit Usaha Customer Good

\begin{tabular}{lccccc}
\hline \multicolumn{1}{c}{ Nama Perusahaan } & 2015 & 2016 & 2017 & 2018 & 2019 \\
\hline Wismilak Inti Makmur & $25 \%$ & $11,79 \%$ & $9 \%$ & $8 \%$ & $7,8 \%$ \\
Akasha Wira International & $19,56 \%$ & $17,89 \%$ & $5 \%$ & $12,6 \%$ & $9,6 \%$ \\
Tempo Scan Pacific & $11,78 \%$ & $9,7 \%$ & $8,92 \%$ & $10,3 \%$ & $14,6 \%$ \\
Sariguna Primatirta & $12,89 \%$ & $10,4 \%$ & $7,80 \%$ & $12,8 \%$ & $9,2 \%$ \\
Integra & $13,7 \%$ & $9,78 \%$ & $8,04 \%$ & $6,4 \%$ & $8,7 \%$ \\
\hline
\end{tabular}

Sumber: Data Penelitian, 2020

Pada Tabel 1, laba atas ekuitas PT Wismilak pada tahun 2015 mengalami penurunan menjadi $13,21 \%$, kemudian terjadi penurunan kembali menjadi $2,79 \%$ hingga tahun 2019 mengalami penurunan 0,2\%. Perusahaan Akasha di Tahun 2015 memiliki laba 19,56\% kemudian terjadi penurunan 17,89 menjadi 1,67\%. Serta kembali mengalami penurunan di tahun 2017 menjadi 12,89\% kemudian mengalami kenaikan 4,6\%. PT. Tempo Scan Pascific mengalami memiliki laba 11,78\% kemudian turun di tahun 2017 menjadi 2,08, kemudian turun kembali di tahun 2017 menjadi 0,78\% serta mengalami kenaikan laba diakhir tahun 2019 menjadi $4,3 \%$. Sedangkan PT. Sariguna Primatirta mengalami penurunan laba selama 5 tahun terakhir dari tahun 2015 yaitu 12,89\% dan di tahun 2019 menjadi 3,69\%. Begitu halnya perusahaan Integra pada tahun 2015 memiliki laba 13,7\% kemudian mengalami penurunan hingga di tahun 2017 menjadi 1,74\%. Laba tersebut kian menurun di tahun 2019 menjadi 0,66\%. Maka dapat dikatakan tidak efektifnya laba atas ekuitas yang semakin menurun sehingga ekuitas yang tidak efisien dapat menurunkan keuntungan yang akan dihasilkan secara bersamaan.

Adapun tujuan dari research ini untuk menganalisa laba atas ekuitas pada stock price. Serta tingkat inflasi pada tahun 2016 ialah 3,03\% pada tahun 2017 menjadi 3,65\% serta melonjak naik pada tahun 2019 menjadi 4,58\%. Sehingga investor atau pihak eksternal tidak akan melakukan pendanaan. Situasi seperti ini sangat mempengaruhi pasar keuangan dan makro ekonomi suatu perusahaan.

$\mathrm{H}_{1}$ : Laba atas ekuitas berdampak terhadap stock price.

Pendanaan meletakkan sekumpulan uang yang ada dengan harapan menerima laba di masa depan (Gunawan, 2019). Pasar modal adalah tempatsbagi berbagai pihak (terutama perusahaan) untuk menjual saham (stock) dan obligasi (bond) (Ogboghro, 2017), sedangkan (Prananingrum et al., 2018) ialah pilihan untuk memperoleh keuntungan jangka Panjang. Hasil penjualan dapat dipergunakan sebagai dana tambahan atau modal perusahaan yang ditingkatkan (Fahtonah, 2015 : 48). Menurut Sutedi, (2013: 86) saham ialah kekayanan dari unit 
usaha. Nonejad, (2019) harga saham adalah harga yang sepakati pada fluktuatifnya stock price. Naoui, (2020) saham ialah bukti harta yang dimiliki dalam dokumen suatu unit usaha. Wagner, (2019) menyatakan ialah dokumen berharga yang dimiliki oleh seseorang dari yang ditanamkan. Namun menurut Kumar Tiwarid Shawkat Hammoudeh, (2020) saham ialah penyertaan modal bagi pihak istimewa.

$\mathrm{H}_{2}$ : Inflasi berdampak terhadap stock price.

Dino (2011 : 3) menyatakan Stock price ialah permintaan dan penawaran investasi yang dilihat dari modal. Fenni, (2015 : 85) mengartikan return on equity adalah rasio menguji sejauh mana perusahaan menggunakan sumber dayanya untuk dapat memberikan pengembalian atas ekuitas. Fathonah, (2015: 61) mengartikan inflasi adalah suatu peristiwa yang menggambarkan situasi harga barang yang mengalami kenaikan dan devaluasi mata uang. Mohamed, (2020) Inflasi ialah kenaikan upah dengan waktu yang tidak bisa ditentukan. Sedangkan Johnson, (2020) berkata Kenaikan harga batang jasa pada periode waktu tidak terduga yang menyebabkan perubahan naiknya barang. Menurut Nonejad, (2020) inflasi yaitu faktor-faktor naiknya harga secara terus-menerus. Nikolaos Anton akakisa, Rangan Guptab Aviral, (2017) menyatakan ROE ialah imbal hasil terhadap modal unit usaha. Stotz, (2019) kontribusi yang akan dihasilkan oleh pemegang saham. Tingkat fluktuatifnya harga secara continue Warr, (2018).

Hasil penelitian Zein, (2019) menunjukkan bahwa Current Ratio, Return On Equity dan Inflasi secara bersamaan memiliki dampak signifikan pada harga saham. Selanjutnya research (Dina, 2017) menunjukkan bahwa ROE berdampak pada harga saham, sedangkan variabel suku bunga SBI Secara parsial tidak ada dampak pada harga saham.

Hendry, (2017) Dampak keuangan terhadap stock price, terdapat dampak secara sendiri nilai ekuitas terhadap stock price. Gunawan, (2019) perubahan Inflasi dan Rasio pada stock price, dengan hasil pada perusahaan industry good berdampak pada investment.

Wagner, (2020) is important foreign currency risk when forecasting share prices, evidence from u.s. companies, implies foreign currency risk against equity levels. Kannadhasan, (2020) the growing equity uncertainty with the resulting relationship impacts oil shocks in various domains. Manowska, (2020) impact of inflation on stock volatility, as a result of predictions with a high sign for the effectiveness of inflation. Kodongo, (2020) the normativeness of stock prices that has developed: bringing business unit results to business entities that increase efficiency in the state market indicates a weak developed market.

Susanto, (2016) pengaruh inflasi, bunga dan nilai tukar pada stock price unit usaha property, dengan hasil bunga dan inflasi sangat berdampak pada stock price.

Indah, (2020) Implementasi exchange rate dan nilai buku pada stock price, dengan hasil hanya nilai buku yang tidak berdampak pada saat turun stock price.

Anna Wulandari, (2018) The strength of financial standards, inflation to stock price Taken together and the examiners themselves are very insulated for the level of stock prices.

$\mathrm{H}_{3}$ : Laba atas ekuitas dan Inflasi berdampak pada terhadap stock price. 


\section{METODE PENELITIAN}

Dilakukannya pengumpulan financial report (Sugiyono, 2014: 240). Data dalam research ini menggunakan dari data financial report dari tahun 2015-2019. Objek unit usaha customer goods industry pada financial report 2015-2019. Sampel yang memenuhi kriteria adalah 10 unit usaha. Stock price (Dino, 2010:120) Price dari tingkat penawaran dan permintaan pada penutupan investasi. Laba atas ekuitas adalah kemampuan unit usaha dalam menghasilkan sumber daya (Fenni, 2015 : 85). Inflasi yaitu (Fathonah, 2015 : 61) Gambaran dimana harga barang mengalami kenaikan maupun penurunan pada tingkat pasar. Data terkumpul melalui laporan keuangan selama 5 tahun dan data pada BPS serta data di Bank Indonesia. Metode analisis dalam penelitian ini dengan melakukan uji statistik deskriptif dan pengujian hipotesis yang terdiri dari pengujian sendiri, uji bersamaan. Penelitian ini menggunakan analisis regresi linier berganda dengan bantuan program stastisical produst and service solutions sebagai teknik analisis data. Sebelum model regresi digunakan untuk menguji hipotesis, dilakukan uji asumsi klasik terlebih dulu. Berikut rumus persamaan analisis regresi linier berganda, yaitu sebagai berikut.

$Y=\alpha+\beta_{1} X_{1}+\beta_{2} X_{2}+\varepsilon$

\section{HASIL DAN PEMBAHASAN}

Penyajian statistik deskriptif bertujuan untuk memberikan gambaran masing-masing variabel yang dapat dilihat dari karakteristiknya seperti nilai rata-rata dan standar deviasi. Nilai rata-rata digunakan untuk mendeskripsikan hasil dari instrumen penelitian. Hasil studi uji statistik dalam penelitian ini ditunjukkan pada Tabel 2.

Tabel 2. Hasil Uji Deskriptif

\begin{tabular}{lccccc}
\hline & Jumlah & Min & Max & Rata-Rata & Std. \\
\hline X1_ROE & 50 & .03050 & .2590 & .1690 & .0690 \\
X2_Inflasi & 50 & 3.90 & 8.90 & 6.90 & 6,78 \\
Y_Harga_Saham & 50 & 119 & 4890 & 1390.00 & 95.50 \\
Valid N (listwise) & 50 & & & & \\
\hline
\end{tabular}

Sumber: Data Penelitian, 2020

Berdasarkan sampel yang memiliki hingga 50 data. Variabel ROE memiliki standar deviasi 0,0690 dengan minimum 0,3050, nilai maksimumnya adalah 0,2590 dan nilai rata-rata adalah 0,1690 . Variabel inflasi memiliki penyimpangan 2,50295 dengan minimal 3,90, nilai maksimum 8,90, dan rata-rata 6,78. Sementara variabel harga saham memiliki standar deviasi 95.50 dengan nilai terendah 119, nilai maksimum adalah 4890 dan harga rata-rata adalah 1390,00.

Tabel 3. Hasil Uji Regresi

\begin{tabular}{rrrrrr}
\hline & B & Error & Beta & $\mathrm{t}$ & Sig. \\
\hline & -170.90 & 345.50 & & -.670 & .712 \\
X1_ROE & 128.907 & 179.908 & .208 & 3.509 & .000 \\
X2_INFLASI & 78.908 & 45.679 & .490 & 1.409 & .069 \\
\hline
\end{tabular}

Sumber: Data Penelitian, 2020

Dari hasil pengujian regresi, dapat dikatakan Dengan value -170.90 menyatakan nilai laba stock price tetap. Laba atas ekuitas terdapat nilai 128,907 
yang artinya naik $1 \%$ bersifat konstan. Variabel Inflasi (X2) value sebesar 78,908. Hal ini berarti jika terjadi naiknya Inflasi sebesar 1\%. Inflasi dengan 78,098 tetap konstan dengan kenaikan value $1 \%$.

Uji-t berfungsi untuk menunjukkan bagaimana pengaruh variabel independen terhadap relativistik (Gita, 2017: 97).

Tabel 4. Hasil Uji Sendiri

\begin{tabular}{lcccrrr}
\hline & \multicolumn{2}{c}{ Unstandardized } & \multicolumn{2}{c}{ Standardized } & & \multicolumn{1}{c}{ Sig. } \\
\cline { 2 - 4 } & $\mathrm{B}$ & Error & Beta & & $\mathrm{t}$ & \multicolumn{1}{c}{ Sig } \\
& -120.470 & 780.290 & & & -690 & .712 \\
X1_ROE & 550.830 & 19.9034 & .920 & 4.870 & .002 \\
X2_Inflasi & 68.081 & 36.767 & .177 & 1.852 & .071 \\
\hline
\end{tabular}

Sumber: Data Penelitian, 2020

Variabel ROE $\left(X_{1}\right)$ mempunyai nilai sig sebesar $0,002<0,05$ sehingga ROE secara parsial berdampak pada stock price. Jika memakai kriteria kedua dengan $t$ hitung sebesar 4,870 lebih dari t tabel 2,014. Inflasi $\left(\mathrm{X}_{2}\right)$ value 0,071 > 0,05 serta $t$ hitung sebesar 1,852 dan $t$ tabel 2,014. Sehingga Inflasi secara sendiri berdampak namun tidak signifikan pada stock price.

Uji-F berfungsi untuk menguji atau menunjukkan implikasi dari semua variabel independen pada variabel yang bergantung pada banyak model regresi linier (Citra, 2017: 140).

Tabel 5. Result Pengujian Bersamaan

\begin{tabular}{|c|c|c|c|c|c|}
\hline & Sum & $\mathrm{df}$ & Rata-Rata & $F$ & Sig. \\
\hline Regression & 4567.390 & 4 & 769.98 & 37.90 & $.001^{\mathrm{b}}$ \\
\hline Residual & 128.879 & 45 & 234.76 & & \\
\hline & 4696.269 & 49 & & & \\
\hline
\end{tabular}

Sumber: Data Penelitian, 2020

Dari data hasil pengujian secara bersamaan value sig 0,001 kurang 0,05 maka laba atas ekuitas dan inflasi secara bersama-sama berdampak pada stock price. Untuk melihat seberapa dampak research yang ada disini (Citra, 2017: 141).

Tabel 6. Result Pengujian Determinan

\begin{tabular}{rrrrr}
\hline $\mathrm{R}$ & $\mathrm{R}$ Square & Adjusted $\mathrm{R}$ & \multicolumn{2}{c}{ Error } \\
\hline $.890^{\mathrm{a}}$ & .890 & .670 & 450.730 \\
\hline
\end{tabular}

Sumber: Data Penelitian, 2020

Melihat dari hasil yang telah dilakukan pada $\mathrm{R}^{2}$ senilai 0,890 . Ini berarti variabel laba atas ekuitas, Inflasi dalam model regresi sebesar $89,0 \%$ sedangkan $11 \%$ tidak di teliti.

ROE dengan sig 0,002 kurang dari dari 0,05. Sehingga laba atas ekuitas berdampak pada stock price. Penelitian (Dina, 2017) yang menunjukkan bahwa ROE memiliki dampak positif pada stock price. Ini menunjukkan semakin bertambah laba atas ekuitas berdampak pada stock price. Tetapi itu tidak cocok dengan hasil penelitian sebelumnya (Edi, 2018) yang menyatakan ROE tanpa berdampak material pada harga saham.

Kemampuan perusahaan dalam menghasilkan keutungan dengan modal sangat berdampak pada pihak internal yang nantinya akan berdampak pada return pemegang saham. Hal ini menunjukkan peningkatan laba atas ekuitas berdampak pada harga saham perusahaan konsumsi yang fluktuatif selama 
tahun 2015-2019, sehingga berimbas pada psikologi pasar. Inflasi pada value signfikan 0,071 lebih dari 0,05. Sehingga inflasi secara sendiri berdampak namun tidak signifikan terhadap stock price.

Hasil Research (Dina, 2017) Menunjukkan bahwa inflasi parsial tidak memiliki dampak signifikan terhadap harga saham. Ini menunjukkan bahwa kenaikan inflasi adalah tanda negatif bagi investor karena akan meningkatkan pendapatan dan pengeluaran perusahaan, sehingga investor akan berpikiran ganda berinvestasi dalam persediaan dan menurunkan harga saham. Hal ini karena inflasi pada objek penelitian yang terjadi selama periode penelitian tidak tinggi. Karena inflasi perusahaan konsumsi yang terjadi selama periode penelitian tidak terlalu tinggi, sehingga para pemakai informasi mudah melakukan investasi. Tetapi tidak cocok dengan hasil peneliti sebelumnya (Putu, 2019) dan (Nina, 2019) yang menunjukkan bahwa inflasi memiliki dampak signifikan terhadap harga saham.

Laba atas ekuitas dan inflasi secara bersama-sama berdampak pada stock price dengan nilai $\mathrm{F}$ hitung 37,90 lebih dari 2,579 dan nilai sig 0,001 kurang dari 0,05, maka laba atas ekuitas berdampak secara bersama pada stock price. Suatu strategi manajemen untuk meningkatkan ekuitas baik dari laba ditahan, serta naiknya tingkat inflasi nantinya akan berdampak pada pengambalian ekuitas. Hal ini juga dikarenakan laba atas ekuitas. Jika dibandingkan dengan objek penelitian laba atas ekuitas cenderung mengalami penurunan, namun perusahaan bisa bertahan untuk menghasilkan keuntungan. Begitu halnya inflasi yang tinggi akan mendatangkan minat untuk investor melakukan investasi. Research mengatakan ROE dan inflasi berdampak pada stock price (Zein, 2019).

\section{SIMPULAN}

ROE berdampak pada harga saham 4,850 lebih dari t tabel 2,014 dan sig 0,002 kurang dari 0,05. Maka laba atas ekuitas berdampak pada stock price. Inflasi dari nilai sig 0,071 melebihi dari 0,05 serta $t$ hitung 1,852 kurang dari $t$ tabel 2,014. Maka inflasi secara sendiri berdampak namun tidak signifikan pada stock price. Laba atas ekuitas dan inflasi secara bersamaan pada harga saham dengan signfikan 0,001 kurang dari 0,05.

Dari research ini memiliki pertimbangan di masa depan yaitu bagi pihak investor untuk menilai unit usaha sebagai bahan investment, serta untuk peneliti selanjutnya menambah variabel rasio atau financial lainnya yang berdampak pada stock price. Maka kedepannya melihat pendekatan lainnya yang dapat mempengaruhinya, menambah faktor-faktor lainnya yang benar-benar berdampak pada situasi close price. Bagi pihak investor lebih pintar dan cerdas memperhatikan faktor-faktor fortofolio dan tidak bergantung pada satu unit perusahaan saja, memperhatikan kecenderungan kesenjangan lainnya yang dapat memicu penurunan dari nilai value yang telah ditanamkan selama bertahun-tahun.

\section{REFERENSI}

Anna Wulandari, M. A. (2018). The strength of financial. Jurnal Akuntansi, 13(2), 2939. https:// doi.org/ISSN: 2654-9247

Citra, G. (2017). Metode Riset (A. Suslia (ed.); Edisi sepuluh). Alfabeta. 
Dewi, A. D. I. R., \& Artini, L. G. S. A. (2016). Pengaruh Suku Bunga SBI, Inflasi, Dan Fundamental Perusahaan Terhadap Harga Saham Indeks LQ-45 Di BEI. E-Jurnal Manajemen Unud, 5(4), 2484-2510.

Dino, K. (2011). Dasar Saham (Edisi 2). Alfabeta.

Edi, (2018). Dampak ROE Pada Saham. Jurnal Manajemen, 5(1), 105-114.

Fathonah, (2015). Investasi. (M. Muhamad (ed.); Edisi 3). Erlangga.

Fenny, (2016). Dasar Investasi (S. Idris (ed.); Kelima). Erlangga.

Ghozali, I. (2016). Aplikasi Analisis Multivariate IBM SPSS 23 (VIII). Badan Penerbit Universitas Diponegoro.

Gunawan, (2019). Pasar Modal (Cetakan ketujuh). Alfabeta.

Hendry, (2017). Dampak Stock Price. Jurnal Auditing, 3(5), 5-18. https://journal.untar.ac.id/index.php/jmieb/article/view/412

Ima Andriyani, C. A. (2019). Pengaruh Suku Bunga, Inflasi, Nilai Buku Terhadap Harga Saham Perusahaan Indeks LQ45. Jurnal Ilmiah Orasi Bisnis, 15(1), 1221. https:// doi.org/ISSN 2085-1375

Johnson, J. D. C. M. G. S. A. (2020). Short-horizon incentives and stock price inflation, Consistent with theoretical predictions. Journal of Corporate Finance, 65(9),

$36-42$. https://doi.org/https://doi.org/10.1016/j.jcorpfin.2019.101501

Kannadhasan, D. D. M. (2020). The asymmetric oil price and policy uncertainty shock exposure of emerging market sectoral equity returns: A quantile regression approach. International Review of Economics \& Finance, 2(6), 12-19. https://doi.org/https:// doi.org/10.1016/j.iref.2020.06.013

Kodongo, K. O. S. M. O. (2020). Insider trading laws and price informativeness in emerging stock markets: The South African case, Importantly. Emerging Markets Review, 43(1), 2-12. https://doi.org/https://doi.org/10.1016/j.ememar.2020.100690

Kumar Tiwarid Shawkat Hammoudeh, N. T. G. G. A. (2020). Effects of Price of Gold on Bombay Stock Exchange Sectoral Indices: New Evidence for Portfolio Risk Management. Research in International Business and Finance, 55(1), 11-19. https:// doi.org/https:// doi.org/10.1016/j.ribaf.2020.101316

Manowska, M. B. F. D. F. R. M. S. (2020). Time-varying inflation risk and stock returns. Journal of Financial Economics, 136(1), 1-10. https://doi.org/https://doi.org/10.1016/j.jfineco.2019.09.012

Mohamed, S. A. A. B. C. X. C. A. (2020). Why do firms manage their stock price levels. Journal of International Financial Markets, Institutions and Money, 67(1), 34-39. https:// doi.org/https://doi.org/10.1016/j.intfin.2020.101220

Naoui, I. C. K. G. bAngham B. B. cKamel. (2020). Modelling the nonlinear relationship between oil prices, stock markets. Research in International Business and Finance, 2(4), 5-13. https://doi.org/https://doi.org/10.1016/j.ribaf.2020.101274

Nikolaos Anton akakisa, Rangan Guptab Aviral, K. T. (2017). Has the correlation of inflation and stock prices changed in the United States over the last two centuries. Research in International Business and Finance, 20(3), 1-12. https://doi.org/https://doi.org/10.1016/j.ribaf.2017.04.005

Ningsih, M. M., \& Waspada, I. (2018). Pengaruh Bi Rate Dan Inflasi Terhadap Indeks Harga Saham Gabungan (Studi Pada Indeks Properti, Real Estate, Dan Building 
Construction, di BEI Periode 2013 - 2017 ) The Effect Of Bi Rate And Inflation On Composite. 3(5), 247-258.

Nonejad, N. (2019). Crude oil price volatility and equity return predictability: A comparative out-of-sample study. International Review of Financial Analysis, 71(1), 12-18. https:/ / doi.org/https:/ / doi.org/10.1016/j.irfa.2020.101521

Nonejad, N. (2020). A comprehensive empirical analysis of the predictive impact of the price of crude oil on aggregate equity return volatility. Journal of Commodity Markets, 20(3), 1-9. https://doi.org/https://www.sciencedirect.com/science/article/abs/pii/S 2405851319300868

Ogboghro, V. I. (2017). The Impart of Inflation and Exchange Rates on Stock Prices in Nigeria. Account and Financial Management Journal, 2(6), 748-757. https://doi.org/10.18535/afmj/v2i6.01

Prananingrum, D. K., Muthalib, D. A., Irfandy, M., \& Rohansyah, M. (2018). Effects of Return on Asset, Return On Equity, Earning Per Share on Corporate Value. The International Journal of Engineering and Science (IJES), 7(3 Ver.I), 6-14. https:/ / doi.org/10.9790/1813-0703010614

Putu, W. G. (2019). Pengaruh Inflasi, Nilai Tukar Rupiah, Suku Bunga SBI pada Indeks Harga Saham Gabungan di BEI. Jurnal Akuansi Universitas Udaya, 2(1), 421-435.

S.Warr, S. vasan K. murthy D. P. R. (2018). Inflation and equity mutual fund flows. Journal of Financial Markets, 1(4), 52-69. https://doi.org/https://doi.org/10.1016/j.finmar.2017.12.001

Stotz, O. (2019). The response of equity prices to monetary policy announcements: Decomposing the announcement day return into cash-flow news. Journal of International Money and Finance, 99(5), 2-11. https://doi.org/https://doi.org/10.1016/j.jimonfin.2019.102069Get rights and content

Suarka, S. W., \& Wiagustini, N. L. P. (2016). Pengaruh Inflasi, Profitabilitas, Struktur Modal, Dan Earning Per Share Terhadap Harga Saham Perusahaan Consumer Goods. E-Jurnal Manajemen, 8(6), 3930-3958. https://doi.org/ISSN : 2302-8912, https:// doi.org/10.24843/EJMUNUD.2019.v08.i06.p23

Sugiyono. (2014). Metode Penelitian Kuantitatif, Kualitatif dan RED (Edisi 21). Alfabeta, ISBN: 1729-2390.

Susanto, B. (2016). Pengaruh Inflasi, Bunga Dan Nilai Tukar Terhadap Harga Saham (Studi Pada: Perusahaan Sektor Properti Dan Real Estate Tercatat BEI). Jurnal Aset (Jurnal Akuntansi Riset), 7(1), 29-38. https:// doi.org/ISSN: 2086-2563

Wagner, P. P. N. (2019). Pricing Equity-Bond Covariance Risk: Between FlightTo-Quality And Fear-Of-Missing-Out. International Review of Financial Analysis, 1(5), 12-19. https://doi.org/https://doi.org/10.1016/j.jedc.2020.104009

Wagner, P. P. N. (2020). Does foreign exchange risk matter to equity research analysts when forecasting stock prices, Evidence from U.S. firms. International Review of Financial Analysis, 72(1), 1-11. https://doi.org/https://www.sciencedirect.com/science/article/abs/pii/S 
$105752192030212 X$

Zein, (2019). Implementasi Current Return On Asset dan Inflasi Pada Stock Price Di Berberbagi Unit Perusahaan. Jurnal Manajemen dan Bisnis. 6(9), 30-40 ISSN:2218-7654. 